\title{
PKC Phosphorylation Regulates mGluR5 Trafficking by Enhancing Binding of Siah-1A
}

\author{
Suk Jin Ko, ${ }^{1,2 \star}$ Kaname Isozaki, ${ }^{3 \star}$ Insook Kim, ${ }^{4}$ Jeong Ho Lee, ${ }^{1,2}$ Ho Jin Cho, ${ }^{1,2}$ Sun Young Sohn, ${ }^{1}$ So Ra Oh, ${ }^{1}$ \\ Steven Park, ${ }^{1}$ Dong Goo Kim, ${ }^{1,2}$ Chul Hoon Kim, ${ }^{1,2,5}$ and Katherine W. Roche ${ }^{3}$ \\ ${ }^{1}$ Department of Pharmacology, Yonsei University College of Medicine, Seoul 120-752, Korea, ${ }^{2}$ Brain Korea 21 Project for Medical Science, Yonsei University \\ College of Medicine, Seoul 120-752, Korea, ${ }^{3}$ National Institute of Neurological Disorders and Stroke, National Institutes of Health, Bethesda, Maryland \\ 20892, ${ }^{4}$ Division of Metabolic Disease, Department of Biomedical Science, National Institutes of Health, Osong 363-951, Korea, and ${ }^{5}$ Severance Biomedical \\ Science Institute, Yonsei University College of Medicine, Seoul 120-752, Korea
}

Glutamate is the major excitatory neurotransmitter in the mammalian CNS and acts on both ionotropic and metabotropic glutamate receptors (mGluRs). The mGluRs are widely distributed in the CNS and modulate a variety of neuronal processes, including neurotransmitter release and ion channel function. In hippocampus and cortex, mGluR5 is highly expressed and plays an important role in the regulation of synaptic plasticity. Calmodulin (CaM) binding dynamically regulates mGluR5 surface expression; however, the mechanisms linking CaM to mGluR5 trafficking are not clear. Recent studies showed that CaM binding to mGluR7 regulates its trafficking in a phosphorylation-dependent manner by disrupting the binding of protein interacting with $\mathrm{C}$ kinase 1 . The E3 ligase seven in absentia homolog (Siah)-1A binds to mGluR5 and competes with CaM binding, making it an intriguing molecule to regulate phosphorylationdependent trafficking of mGluR5. In the present study, we find that CaM competes with Siah-1A for mGluR5 binding in a phosphorylation-dependent manner in rat hippocampal neurons. Specifically, phosphorylation of mGluR5 S901 favors Siah-1A binding by displacing CaM. We identified critical residues regulating Siah-1A binding to mGluR5 and showed that binding is essential for the Siah-1A effects on mGluR5 trafficking. Siah-1A binding decreases mGluR5 surface expression and increases endosomal trafficking and lysosomal degradation of mGluR5. Thus CaM-regulated Siah-1A binding to mGluR5 dynamically regulates mGluR5 trafficking. These findings support a conserved role for CaM in regulating mGluR trafficking by PKC-dependent regulation of receptor-binding proteins.

\section{Introduction}

Metabotropic glutamate receptors (mGluRs) exert neuromodulatory effects at the majority of excitatory synapses (Niswender and Conn, 2010). The mGluRs (mGluR1-mGluR8) are G-proteincoupled receptors (GPCRs), which are subdivided into three groups based on agonist/antagonist selectivity, sequence homology, and G-protein coupling. The group I mGluRs, mGluR1 and mGluR5, couple to the $\mathrm{G}_{\mathrm{q} / 11}$ family of $\mathrm{G}$-proteins and activate phospholipase $\mathrm{C}$, leading to the production of diacylglycerol and inositol 1,4,5-

Received April 23, 2012; revised Sept. 18, 2012; accepted Sept. 22, 2012.

Author contributions: C.H.K. and K.R. designed research; S.J.K., K.I., I.K., J.H.L., H.J.C., S.Y.S., S.R.O., and S.P. performed research; D.G.K., C.H.K., and K.R. analyzed data; C.H.K. and K.W.R. wrote the paper.

This work was supported by Basic Science Research Program through the National Research Foundation of Korea funded by the Ministry of Education, Science, and Technology (No. 2011-0003351 and 2011-0001174) (to C.H.K.), by the Japan Society for the Promotion of Science Research Fellowship for Japanese Biomedical and Behavioral Researchers at the National Institutes of Health (to K.I.) and by the National Institute of Neurological Disorders and Stroke Intramural Research Program (to K.W.R.). We thank the Yonsei-Carl Zeiss Advanced Imaging Center at Yonsei University College of Medicine and Dr. Carolyn Smith at National Institute of Neurological Disorders and Stroke Light Imaging Facility for technical assistance. The $\alpha$-tubulin monoclonal antibody developed by J. Frankel and E.M. Nelsen was obtained from the Developmental Studies Hybridoma Bank developed under the auspices of the $\mathrm{Na}$ tional Institute of Child Health and Human Development and maintained by the University of lowa, Department of Biology, lowa City, lowa.

*S.J.K. and K.I. contributed equally to this work.

The authors declare no competing financial interests.

Correspondence should be addressed to Chul Hoon Kim, 134 Shinchon-dong, Seodaemun-gu, Seoul 120-752, Korea.E-mail: kimhoon@yuhs.ac.

DOI:10.1523/JNEUROSCI.1964-12.2012

Copyright $\odot 2012$ the authors $\quad 0270-6474 / 12 / 3216391-11 \$ 15.00 / 0$ trisphosphate and release of intracellular calcium (Niswender and Conn, 2010). mGluR5 modulates synaptic transmission and is involved in activity-dependent short-term and long-term synaptic plasticity (Lüscher and Huber, 2010). In addition, mGluR5 has been implicated in the pathophysiology of many neurological and psychiatric disorders, such as pain, anxiety, schizophrenia, drug addiction, and Alzheimer's disease (Krystal et al., 2010). Notably, overstimulation of mGluR5 is closely related to the pathophysiology of fragile $\mathrm{X}$ mental retardation syndrome, indicating that mGluR5 may represent a potential pharmacologic target for the disease (Dölen et al., 2007).

Excitatory synapses are extremely dynamic and expression of postsynaptic proteins is tightly regulated. In particular, the trafficking of surface receptors can be rapidly modified in response to synaptic activity. As with many GPCRs, mGluR5 endocytosis and intracellular sorting are important mechanisms for fine-tuning mGluR5 signaling and preventing receptor overstimulation. The surface expression of mGluR5 is dynamically regulated by calmodulin (CaM). Receptor activation triggers PKC phosphorylation of a critical residue on the mGluR5 C terminus, serine 901 (S901), which disrupts the binding of CaM to the receptor (Lee et al., 2008). The result is increased internalization and decreased surface expression. However, the underlying mechanism of CaM-dependent mGluR5 trafficking is unknown.

$\mathrm{CaM}$ is a ubiquitously expressed calcium-binding protein (Chin and Means, 2000) particularly abundant in the brain. CaM 
regulates the synaptic plasticity of excitatory synapses by forming functional interactions with NMDA receptors and voltage-gated calcium channels (Xia and Storm, 2005). Numerous neuronal GPCRs, including dopamine, serotonin, opioid, and adenosine receptors, have been reported to bind CaM (Wang et al., 1999; Turner et al., 2004; Turner and Raymond, 2005; Navarro et al., 2009). We recently showed that the surface expression of the presynaptic mGluR7 receptor is dynamically regulated by PKC phosphorylation and CaM binding (Suh et al., 2008). However, for mGluR7, neuronal activities trigger dephosphorylation of the major PKC phosphorylation site on the mGluR7 C terminus and promote CaM binding. Like mGluR5, agonist stimulation of mGluR7 leads to decreased surface expression. Interestingly, CaM affects mGluR7 trafficking by competing with protein interacting with $\mathrm{C}$ kinase 1 (PICK1) binding in a phosphorylation state-dependent manner. However, mGluR5 does not bind to PICK1, so the CaM binding to mGluR5 must regulate trafficking via a different set of protein interactions.

CaM competes with the E3 ligase seven in absentia homolog (Siah)-1A for mGluR5 binding in vitro (Ishikawa et al., 1999), and researchers have demonstrated that Siah-1A degrades mGluR1 and mGluR5 (Moriyoshi et al., 2004). Because S901 phosphorylation regulates the interaction between $\mathrm{CaM}$ and mGluR5 (Lee et al., 2008) and Siah-1A is present in synaptic vesicles and endosomes (Wheeler et al., 2002), we hypothesized that CaM-dependent regulation of mGluR5 trafficking could be attributed to the competitive binding of $\mathrm{CaM}$ and Siah-1A. Here we show that phosphorylation of mGluR5 displaces CaM and enhances the interaction of Siah-1A with mGluR5, leading to decreased levels of mGluR5 on the cell surface. We define critical elements of the Siah-1A-binding site on the mGluR5 C terminus, which are distinct from the CaM-binding site. Using specific mutations, we show that the direct interaction between Siah-1A and mGluR5 is necessary for Siah-1A effects on receptor trafficking. Furthermore, we investigate the role of Siah-1A in neurons and find it specifically regulates mGluR5 expression. Together, these results support a dynamic model in which activity-induced receptor phosphorylation regulates the trafficking of mGluRs through receptor-CaM interactions.

\section{Materials and Methods}

Cell culture and transfection. HeLa cells were maintained in DMEM containing $10 \%$ fetal bovine serum in $5 \% \mathrm{CO}_{2} / 95 \%$ air at $37^{\circ} \mathrm{C}$. The cells were transfected with DNA constructs using Polyplus-transfection reagent (Polyplus-transfection) according to the manufacturer's instructions. Primary hippocampal neuronal cell cultures were produced and maintained according to the method described previously (Suh et al., 2008) with some modifications. All experiments were performed in accordance with the Yonsei University College of Medicine Animal Care and Use Committee or NIH Guide for the Care and Use of Laboratory Animals. Briefly, primary hippocampal neuron cultures were prepared from embryonic day 18 Sprague Dawley rat embryos of either sex. The hippocampi were dissected, and the cells were dissociated by trituration using a fine-bored Pasteur pipette. The cells were then plated onto cover glasses coated with poly-L-lysine. The hippocampal cells were grown in Neurobasal Medium (Invitrogen) supplemented with B-27 (2\%) and L-glutamine $(2 \mathrm{~mm})$. The cultures were maintained at $37^{\circ} \mathrm{C}$ in $5 \% \mathrm{CO}_{2} /$ 95\% air.

Constructs and siRNA. We created the pCBA mammalian expression vector using a chicken $\beta$-actin promoter. mGluR5 cDNA was subcloned into pCBA to produce pCBA-mGluR5. Site-directed mutagenesis was performed using pCBA-mGluR5 as a template to make S901A, S901D, T913D, I916A, and S901D/I916A mutants. A Myc epitope was inserted between amino acids 22 and 23 of the $\mathrm{N}$ terminus of pRK5-mGluR5, resulting in pRK5-N-Myc-mGluR5. Cam2 was subcloned into the
pcDNA3.1 and pPTuner-IRES vectors (Clontech). Siah-1A cDNA was subcloned into the pCI-neo and pPTuner-IRES vectors. The cDNA encoding the first one-third of the $\mathrm{C}$ terminus (Cprox) of mGluR5 was subcloned into the pGEX-4T1 (GE Health) and pBHA vectors. Siah-1A was subcloned into the pRSET bacterial expression vector (Invitrogen) and the pEGFP-C vector (Clontech). Yeast plasmids encoding mutant forms of mGluR5 Cprox (S901A, S901D, T913A, T913D, V915A, I916A, I916E, and P918A) were generated from pBHA-mGluR5 Cprox by sitedirected mutagenesis. The sequences of all mutants were confirmed by sequencing. The human Siah-1A siRNA pool (L-012598-00-0050) was purchased from Thermo Scientific, and human hepatocyte growth factor-regulated tyrosine kinase substrate (Hrs) shRNA was purchased from Sigma-Aldrich.

Western blot and immunoprecipitation. For Western blotting, cells were washed twice with cold PBS and solubilized at $4^{\circ} \mathrm{C}$ for 15 min in PBS containing 1\% Triton X-100 and the Complete protease inhibitor mixture (Roche). The cell lysates were then cleared by centrifugation at $12,000 \times g$ for $10 \mathrm{~min}$ at $4^{\circ} \mathrm{C}$. The samples were resolved by SDS-PAGE and transferred onto polyvinylidene fluoride membranes. The membranes were blocked with $0.5 \%$ nonfat milk plus $0.1 \%$ Tween 20 for $2 \mathrm{~h}$, and protein levels were analyzed by immunoblotting with primary antibodies, including mGluR5 (Epitomics), mGluR7 (Millipore), FLAG M2 (Sigma-Aldrich), Siah-1A (Abcam), CaM (Millipore), neomycin phosphotransferase II (NPT-II, Millipore), $\alpha$-tubulin (Hybridoma Bank), and $\beta$-actin (Santa Cruz Biotechnology). For immunoprecipitation, the lysates were homogenized and clarified by centrifugation at $12,000 \times g$ for $10 \mathrm{~min}$ at $4^{\circ} \mathrm{C}$. The supernatants were incubated with primary antibodies overnight at $4^{\circ} \mathrm{C}$, and the immune complexes were captured by protein A agarose (GE Health) for $2 \mathrm{~h}$ at $4^{\circ} \mathrm{C}$. The eluted immunoprecipitates from the protein A agarose were then subjected to Western blotting.

Real-time quantitative PCR. The SYBR Green method was used for all real-time quantitative PCR experiments. Reverse transcription was performed with $2 \mu \mathrm{g}$ of total RNA using Superscript III reverse transcriptase (Invitrogen). PCRs were subsequently established using $2 \mu \mathrm{l}$ of synthesized cDNA, 250 nм primer pairs, and $10 \mu$ l of SYBR Green PCR Master Mix (Applied Biosystems) in a total reaction volume of $20 \mu \mathrm{l}$. The reactions were run with the following cycling conditions: $10 \mathrm{~min}$ at $95^{\circ} \mathrm{C}$, then 40 cycles of $95^{\circ} \mathrm{C}$ for $20 \mathrm{~s}, 60^{\circ} \mathrm{C}$ for $40 \mathrm{~s}$, and $70^{\circ} \mathrm{C}$ for $30 \mathrm{~s}$. The values were normalized to that of the housekeeping gene $\beta$-actin.

Pull-down assay and PKC in vitro phosphorylation. The GST-mGluR5 Cprox fusion protein was purified using glutathione Sepharose $4 \mathrm{~B}$ beads according to the manufacturer's instructions (GE Health). The GSTmGluR5 Cprox bound to Sepharose beads was then incubated with active PKC ( $25 \mathrm{ng}$, Promega) in a phosphorylation buffer containing $20 \mathrm{~mm}$ HEPES, $1.67 \mathrm{~mm} \mathrm{CaCl}_{2}, 1 \mathrm{~mm}$ DTT, $10 \mathrm{~mm} \mathrm{MgCl}_{2}$, and 1 pmol of $[\gamma-$ ${ }^{32} \mathrm{P}$ ]ATP $(3000 \mathrm{Ci} / \mathrm{mmol})$ at $30^{\circ} \mathrm{C}$ for $30 \mathrm{~min}$. Phosphorylated fusion proteins were incubated with purified CaM (Sigma-Aldrich) or the Siah-1A His-fusion protein at $4^{\circ} \mathrm{C}$ for $2 \mathrm{~h}$. The glutathione Sepharose $4 \mathrm{~B}$ beads were washed three times, and the bound proteins were eluted by boiling in $2 \times$ SDS sample buffer for $5 \mathrm{~min}$. The samples were then analyzed by Western blotting with CaM or Siah-1A antibodies. PKC phosphorylation of mGluR5 S901 was detected using the S901 phosphorylation state-specific antibody described previously (Lee et al., 2008).

Biotinylation assay. HeLa cells transfected with mGluR5 wild-type (WT), mutants, or Siah-1A were washed with PBS and incubated with EZ-Link Sulfo-NHS-SS-Biotin (Pierce) in PBS for $20 \mathrm{~min}$ at $4^{\circ} \mathrm{C}$. The cells were washed three times with cold PBS with $50 \mathrm{~mm}$ glycine to quench and remove excess biotin reagents. The cells were lysed with $1 \%$ Triton X-100, and the lysates were cleared by centrifugation at 14,000 $\mathrm{rpm}$ for $10 \mathrm{~min}$ at $4^{\circ} \mathrm{C}$. The supernatant was then incubated with NeutrAvidin agarose resin (Pierce) for $2 \mathrm{~h}$ at $4^{\circ} \mathrm{C}$. The resin was washed four times with PBS containing $1 \%$ Triton $\mathrm{X}-100$, and the bound proteins were eluted by mixing and incubating with $2 \times$ sample buffer at $37^{\circ} \mathrm{C}$ for $30 \mathrm{~min}$. The eluted proteins were analyzed by Western blotting. For the endocytosis assay, HeLa cells transfected with mGluR5 WT or mGluR5 S901A mutant were incubated with EZ-Link Sulfo-NHS-SS-Biotin in PBS for $20 \mathrm{~min}$ at $4^{\circ} \mathrm{C}$. The cells were treated with glutamate $(100 \mu \mathrm{M})$ for $5 \mathrm{~min}$ at $37^{\circ} \mathrm{C}$ and then the remaining biotinylated proteins on the cell 
surface were cleaved using $50 \mathrm{~mm}$ reduced glutathione (Roche). After cell lysis, NeutrAvidin agarose resin was added to the lysates for $2 \mathrm{~h}$ at $4^{\circ} \mathrm{C}$. After washing the resin, bound proteins were eluted and then subjected to Western blotting.

Yeast two-hybrid assay. A yeast two-hybrid assay was performed using the L40 yeast strain to detect the interaction between the mGluR5 C terminus and Siah-1A. pBHA (LexA-DNA binding domain fusion vector)-mGluR5 Cprox or its mutants and pGAD (GAL4-activation domain fusion vector)-Siah-1A were cotransformed into L40 yeast. The yeasts were grown in synthetic complete medium lacking tryptophan and leucine. Yeast colonies were picked up and dissolved in 10-fold serial dilutions in sterile water in a 96-well plate. Using a replica plater, the yeasts in each well were plated as a spot on a synthetic complete medium agar plate lacking tryptophan, leucine, and histidine. The plates were then placed in a $30^{\circ} \mathrm{C}$ incubator for $2-3 \mathrm{~d}$.

Immunostaining for surface expression. HeLa cells grown on glass coverslips were transfected with Myc-mGluR5 and GFP-Siah-1A. Live transfected cells were washed once in ice-cold PBS and labeled with the mouse Myc (9E10) antibody (Sigma-Aldrich) for $15 \mathrm{~min}$ on ice. After three washes in ice-cold PBS, the cells were fixed with $4 \%$ paraformaldehyde in PBS for $15 \mathrm{~min}$ at room temperature and then permeabilized in PBS with $0.25 \%$ Triton X-100 for $5 \mathrm{~min}$. The coverslips were then incubated with rabbit mGluR5 and chicken GFP antibodies (Invitrogen) for $30 \mathrm{~min}$. Following multiple washes with PBS, the cells were incubated with Alexa 488 anti-chicken, Alexa 568 anti-rabbit, and Alexa 647 anti-mouse secondary antibodies (Invitrogen) at 1:500 for $30 \mathrm{~min}$. The coverslips were washed and mounted with the ProLong Antifade Kit (Invitrogen). The cells were visualized using a Zeiss LSM710 confocal microscope (Carl Zeiss).

Primary cultured hippocampal neurons were transfected with EGFP or Siah-1A-EGFP and surface receptor was monitored using a rabbit mGluR5 $\mathrm{N}$ terminus antibody (Alomone). Alexa 568 anti-rabbit antibody was used as a secondary antibody. Images of EGFP-positive cells were captured and mGluR5 fluorescence intensities were analyzed using MetaMorph software (Molecular Devices).

Proximity ligation assay. The proximity ligation assay (PLA) was performed using the Duolink assay kit (Olink Bioscience) according to the manufacturer's instructions. Primary cultured hippocampal neurons grown on glass coverslips were fixed with $4 \%$ paraformaldehyde, permeabilized with $0.1 \%$ Triton X-100 in PBS, and incubated with the Duolink blocking solution for $30 \mathrm{~min}$ at $37^{\circ} \mathrm{C}$. A pair of mGluR5 and Siah-1A antibodies was then loaded onto the cells in a humid chamber. After overnight incubation at $4^{\circ} \mathrm{C}$, the primary antibody solution was tapped off from the coverslips. After washing three times with PBS, the coverslips were incubated with the PLA probe solution for $2 \mathrm{~h}$ and then subjected to hybridization, ligation, and amplification. The cells were incubated with detection solution in a preheated humid chamber for $60 \mathrm{~min}$ at $37^{\circ} \mathrm{C}$. After mounting, cells were visualized with the LSM710 confocal microscope (Carl Zeiss). Serial optical sections at $0.22 \mu \mathrm{m}$ intervals were converted to maximal projection. Quantification of confocal experiments was performed using MetaMorph software (Molecular Devices). Acquired images were thresholded, and the integrated intensities of mGluR5-Siah-1 interaction in neurons were measured in $50 \mu \mathrm{m}$ dendritic segments. We evaluated dendritic fragments $50 \mu \mathrm{m}$ from the cell bodies of each hippocampal neuron. The data were averaged from 150 to 200 dendritic fragments from at least six independent experiments.

Statistical analysis. All data are reported as means \pm SEM. Statistical comparisons were made using two-tailed unpaired $t$ test or one-way ANOVA followed by Bonferroni-Dunn post hoc test for multiple comparisons as appropriate. Data were analyzed using Prism software (GraphPad).

\section{Results \\ A phosphomimetic mutation of S901 affects the stability of mGluR5}

Siah-1A is an E3 ligase that binds to the $\mathrm{C}$ terminus of mGluR5 (Fig. 1A) and regulates the stability of mGluR5. We have shown previously that $\mathrm{S} 901$ phosphorylation inhibits the binding of
CaM to mGluR5 (Lee et al., 2008) (Fig. 1A). Because CaM competes with Siah-1A for binding to group I mGluRs in vitro (Ishikawa et al., 1999), we wanted to test whether the S901 phosphomimetic mutation (S901D) could also modulate Siah-1A binding and therefore affect mGluR5 protein levels. We expressed mGluR5 (WT, S901D, or S901A) in HeLa cells and measured the protein expression levels by Western blotting using anti-mGluR5 antibodies. The expression level of mGluR5 S901D was low compared with mGluR5 WT and mGluR5 S901A (Fig. $1 B)$. Importantly, the expression of NPT-II, which is encoded from the same DNA construct containing mGluR5, was also measured to confirm equal transfection of DNA constructs. Realtime PCR results indicated that the $\$ 901$ mutations did not alter mGluR5 mRNA expression levels, which excluded the possibility that the decreased expression of the mGluR5 S901D mutant was due to reduced mGluR5 mRNA expression (Fig. 1C).

To assess whether the S901D mutation affected the stability of mGluR5, we performed a cycloheximide chase experiment and measured mGluR5 degradation. Protein synthesis was blocked by treatment with cycloheximide, and receptor expression levels were monitored for $6 \mathrm{~h}$. Compared with the half-life of mGluR5 WT, there was a significant decrease in the half-life of mGluR5 S901D, suggesting that the S901D mutation may accelerate the degradation of mGluR5 as a result of diminished CaM and increased Siah-1A binding to mGluR5 (Fig. 1D,E).

\section{Siah-1A is required for the accelerated degradation of mGluR5 S901D}

To evaluate the role of Siah-1A binding in mGluR5 degradation, HeLa cells were cotransfected with mGluR5 and Siah-1A, and protein expression levels were measured by Western blotting. Siah-1A overexpression reduced mGluR5 protein levels (Fig. $2 A$ ), but not mGluR7 (Fig. 2B), which is consistent with a previous report (Moriyoshi et al., 2004). We next compared the effect of Siah-1A expression on mGluR5 WT and S901D levels. HeLa cells were cotransfected with siRNA against Siah-1A and mGluR5 WT or mGluR5 S901D construct. In control samples, mGluR5 S901D was markedly decreased compared with mGluR5 WT (Fig. 2C). However, when Siah-1A was knocked down with siRNA, mGluR5 S901D was not significantly decreased compared with mGluR5 WT, revealing Siah-1A conferred differences in mGluR5 stability between mGluR5 WT and mGluR5 S901D.

Considering previous data showing that mGluR5 S901D has reduced CaM binding (Lee et al., 2008), we suspected that the increased binding of Siah-1A to mGluR5 S901D would decrease mGluR5 protein levels. To specifically examine whether the reduction in mGluR5 S901D protein levels was caused by the differential binding of CaM and Siah-1A, we transfected cells with mGluR5 WT or mGluR5 S901D. Receptor was immunoprecipitated using the mGluR5 antibody, and immunoblotting was performed using CaM and Siah-1A antibodies. The S901D mutant showed a marked increase in Siah-1A binding and a significant decrease in CaM binding (Fig. 2D). This suggests that the S901D mutation favored Siah-1A over CaM binding, causing the S901D mutant protein to be less stable than the mGluR5 WT protein.

Next, using an in vitro pull-down assay, we examined whether Siah-1A binding was directly affected by S 901 phosphorylation in the absence of CaM. We discovered that CaM binding to the mGluR5 Cprox GST-fusion protein is inhibited by PKC phosphorylation of S901; however, binding of purified Siah-1A in the absence of CaM was not affected. These findings indicate that Siah-1A binding was affected by the interaction with $\mathrm{CaM}$ and not by the $S 901$ phosphorylation status per se (Fig. 2E). 


\section{CaM and Siah-1A competition for mGluR5 in situ}

To investigate whether CaM and Siah-1A compete for binding to mGluR5 in situ, $\mathrm{CaM}$ and Siah-1A were cotransfected into HeLa cells with mGluR5 WT. We found that mGluR5 WT coimmunoprecipitated with both endogenous CaM and Siah-1A (Fig. 3A). CaM overexpression increased binding of CaM to mGluR5 while decreasing the amount of Siah-1A binding. Accordingly, Siah-1A overexpression increased its binding to mGluR5, but decreased CaM binding, indicating that CaM and Siah-1A antagonize one another for mGluR5 binding in our cell system (Fig. 3A).

To assess whether increased CaM binding can regulate mGluR5 receptor stability, which is dependent on Siah-1A binding to the receptor, we used a CaM or Siah-1A fused to a destabilization domain (DD). The DD is responsible for the constitutive and rapid degradation of fused proteins (Banaszynski et al., 2006). Shield1 is a reagent that binds to the DD and protects the DD-fused protein from degradation (Fig. 3B). We used this system to sort out the possible trans effects on promoters between DNA constructs, which have long been known to be a confounding factor in cotransfection experiments (Farr and Roman, 1992). HeLa cells were cotransfected with mGluR5 WT plus CaM or Siah-1A DNA constructs fused to the DD. In cells transfected with DDSiah-1A, Shield1 treatment increased the expression of Siah-1A and decreased mGluR5 protein levels (Fig. 3C, right), which is consistent with the data from our Siah-1A cDNA overexpression experiment shown in Figure $2 A$. Importantly, upon treatment with Shield1, CaM expression and the amount of mGluR5 WT increased in cells transfected with DD-CaM (Fig. 3C, left). These results indicate that CaM and Siah-1A compete with one another to regulate mGluR5 stability.

\section{CaM and Siah-1A interactions with} mGluR5 regulate receptor trafficking

To investigate whether mGluR5 regulation by CaM and Siah-1A competition affects the cell surface expression of mGluR5, we performed a biotinylation assay. Siah-1A and mGluR5 WT were coexpressed in HeLa cells, and surface biotinylation was performed followed by purification of biotinylated proteins and Western blotting for mGluR5. We found that Siah-1A decreased the amount of surface mGluR5, but did not affect the level of mGluR7 surface expression (Fig. $4 A)$. We next compared the surface expression of mGluR5 WT, S901D, and S901A. Similar to the Western blot data from total cell lysates, the S901D mutation reduced mGluR5 surface
B

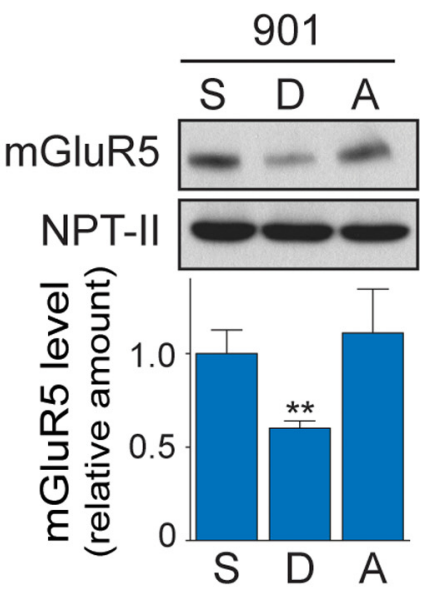

E

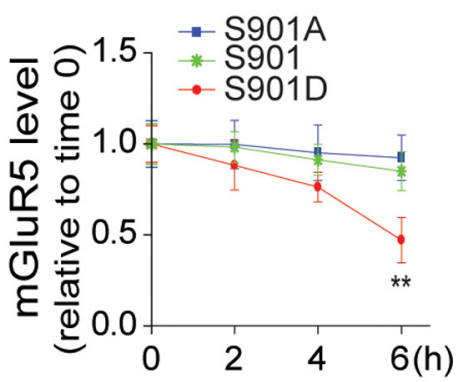

Figure 1. S901 phosphomimetic mutation affects mGluR5 protein stability. $A$, Schematicfigure showing competition between CaM and Siah-1A for mGluR5 binding. Colored lines along amino acid sequences represent binding motifs for each protein. $\boldsymbol{B}$, HeLa cells were transfected with mGluR5 WT (S), S901D, or S901A mutants. mGluR5 expression levels were analyzed by Western blotting. NPT-II is expressed from the same DNA construct as the mGluR5 gene (pCBA-mGluR5). NPT-Il expression detected by the NPT-Il antibody was used as an equal transfection control. The histogram represents blot quantification from at least four independent experiments. mGluR5 levels were normalized to NPT-II and expressed as fold changes over that of control cells expressing mGluR5 WT. Data represent the mean values ( \pm SEM). One-way ANOVA $\left(F_{(2,12)}=13.41, p=0.0009\right)$, followed by Bonferroni-Dunn posthoctest for multiple comparisons. ${ }^{* *} p<0.01$ compared with mGluR5 WT (S). C, Cells were transfected with mGluR5 WT (S), S901D, or S901A mutants. mGluR5 mRNA expression was measured using quantitative real-time PCR. D, Cells expressing WT (S), S901D, or S901A mutants were pretreated with cycloheximide (200 $\mu \mathrm{g} / \mathrm{ml})$ for $2 \mathrm{~h}$ and then collected at the indicated times. Proteins from cell lysates were separated by SDS-PAGE and analyzed by Western blotting. $E$, mGluR5 band intensities in the chase experiment were plotted relative to those at the zero time point. Data represent the mean values ( \pm SEM). One-way ANOVA $\left(F_{(2,12)}=121.5, p<0.0001\right)$, followed by Bonferroni-Dunn post hoc test for multiple comparisons. ${ }^{* *} p<0.01$ compared with mGluR5 WT (S).

expression compared with mGluR5 WT or mGluR5 S901A (Fig. $4 B$, upper). The effects of Siah-1A on mGluR5 surface expression could be mediated by changes in trafficking to lysosomes and subsequent degradation. To test this hypothesis, we treated cells with the lysosomal inhibitor chloroquine. Interestingly, we found that chloroquine treatment inhibited the accelerated degradation of mGluR5 S901D, but the decrease in mGluR5 S901D surface expression compared with mGluR5 WT was not affected, indicating that Siah-1A binding affects surface expression of mGluR5 independent of receptor degradation (Fig. $4 B$, lower). 
A

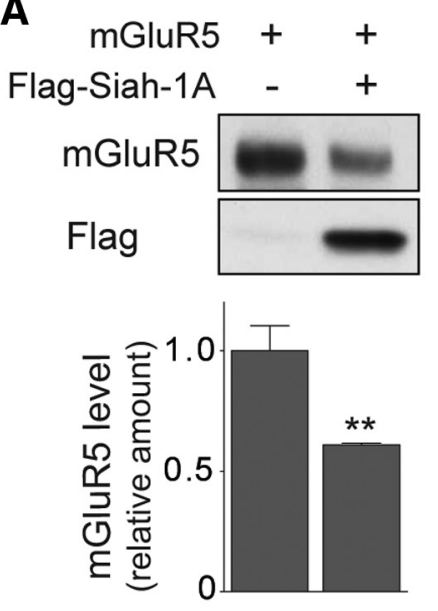

D
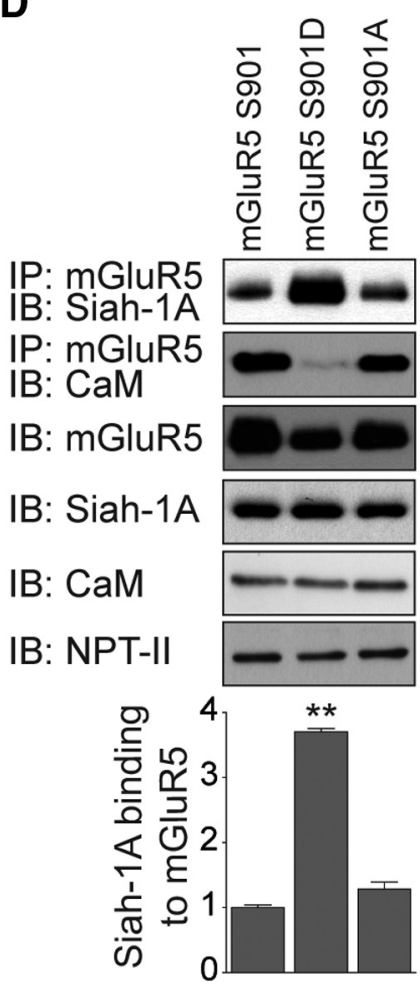

B

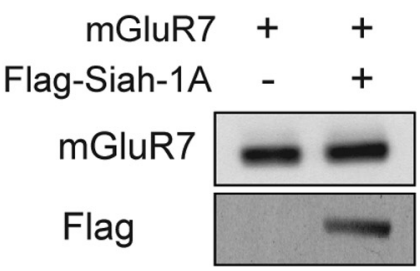

C

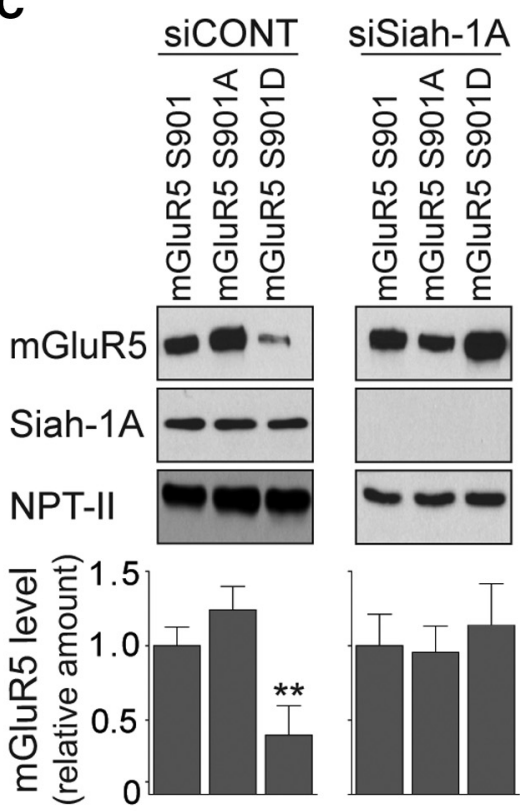

E

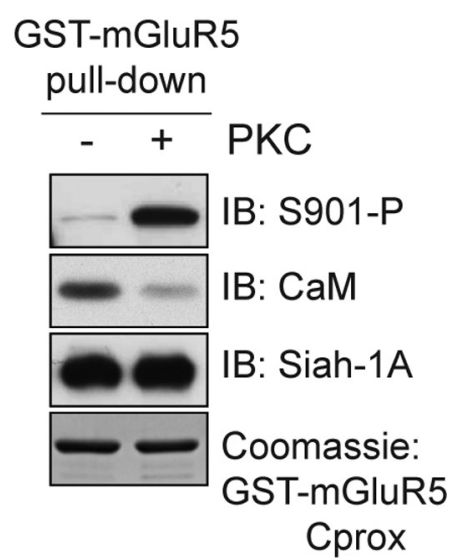

Figure 2. Siah-1A regulation of mGluR5 stability. $\boldsymbol{A}$, HeLa cells were transfected with $\mathrm{mGluR5}$ and either a control vector or the FlagSiah-1A construct. Western blotting was performed to detect the levels of mGluR5 and Siah-1A using mGluR5 and Flag antibodies. Results are the averages of at least four independent experiments. Unpaired $t$ test $\left({ }^{* *} p<0.01\right)$ versus mGluR5 WT (S). B, HeLa cells were transfected with mGluR7 and either a control vector or the Flag-Siah-1A construct. Western blotting was performed. C, Cells expressing mGluR5 WT (S), S901D, or S901A mutants were transfected with a siRNA pool against Siah-1A. Changes in mGluR5 and Siah-1A expression were detected by Western blotting. siCONT indicates nontargeted control siRNA pool. D, Lysates from the cells transfected with mGluR5 WT (S), S901D, or S901A mutants were immunoprecipitated with mGluR5 antibodies, and bound endogenous Siah-1A and CaM were immunoblotted with their respective antibodies. $C, D$, mGluR5 levels were normalized to NPT-Il and expressed as fold changes over that of control cells expressing mGluR5WT. Data represent the mean values ( \pm SEM). One-way ANOVA $\left(\boldsymbol{C}: F_{(2,12)}=22.50, p<0.0001 ; D: F_{(2,9)}=536.6\right.$, $p<0.0001$ ), followed by Bonferroni-Dunn post hoc test for multiple comparisons. ${ }^{* *} p<0.01$ compared with mGluR5 WT (S).E, mGluR5 Cprox GST-fusion proteins were phosphorylated by PKC, and a GST pull-down assay was performed for CaM and Siah-1A binding. mGluR5 Cprox GST-fusion proteins were incubated with purified CaM or Siah-1A, respectively, for binding reactions. The resulting blots were visualized using S901 phosphorylation state-specific, CaM, and Siah-1A antibodies.

Because Siah-1A is an E3-ligase, we tested whether the E3ligase activity is required for the effect of Siah-1A on mGluR5 levels using the Siah-1A H59Y mutant devoid of the E3-ligase activity. We found that the Siah-1A H59Y mutant did not affect
mGluR5 protein levels (Fig. 4C). We next investigated the regulation of mGluR5 trafficking by Siah-1A by testing for a potential interaction with Hrs. Hrs is a key component of the ESCRT-0 complex, which engages ubiquitinated cargo proteins and sorts them to multivesicular endosomes, an essential step for lysosomal degradation of membrane proteins (Wollert et al., 2009). We performed a coimmunoprecipitation assay and demonstrated that mGluR5 binds to Hrs in HeLa cells transfected with mGluR5 WT and Hrs (Fig. 4D). mGluR5 S901D bound more to Hrs compared with mGluR5 WT (Fig. 4E), suggesting that Hrs binding is also dependent on the phosphorylation status of S901. We also examined the effect of Hrs knockdown on mGluR5 protein stability and discovered that the stability of mGluR5 WT increased after Hrs inhibition (Fig. 4F). Interestingly, Hrs knockdown rescued the total expression levels of mGluR5 S901D to almost mGluR5 WT levels, indicating that Hrs is an important contributor to the reduced stability of the S901D mutant. Together, these results provide evidence that Siah-1A can regulate mGluR5 trafficking through the endosomal pathway. Next, we tested whether S901 phosphorylation can initiate endocytosis because receptor phosphorylation initiates receptor internalization in many GPCRs. Following a short (5 $\mathrm{min}$ ) treatment of glutamate, we observed endocytosis of both mGluR5 WT and S901A, suggesting that $\mathrm{S} 901$ phosphorylation and subsequent changes in $\mathrm{CaM}$ and Siah-1A binding are not an absolute prerequisite for triggering mGluR5 endocytosis (Fig. $4 G$ ).

Defining the critical residues for Siah$1 \mathrm{~A}$ binding and mGluR5 trafficking To complement our experiments on the mGluR5 S901D mutant, which showed changes in CaM binding but did not directly affect Siah-1A binding, we next identified the amino acids important for Siah-1A binding. We chose to focus on residues that resembled the classic Siah1A-binding motif (Fig. 5A), which have been reported previously (House et al., 2003). Although mGluR5 was not included in the list of proteins possessing a Siah-1A-binding motif, similar and conserved sequences are present in the mGluR5 $\mathrm{C}$ terminus and overlap with the reported Siah-1A-binding domain (Fig. $5 A$ ). Therefore, we made a series of point mutations within the putative Siah-1A-binding region and performed yeast twohybrid assays. Interestingly, mutating isoleucine 916 (I916) to alanine or aspartic acid completely disrupted Siah-1A binding to 


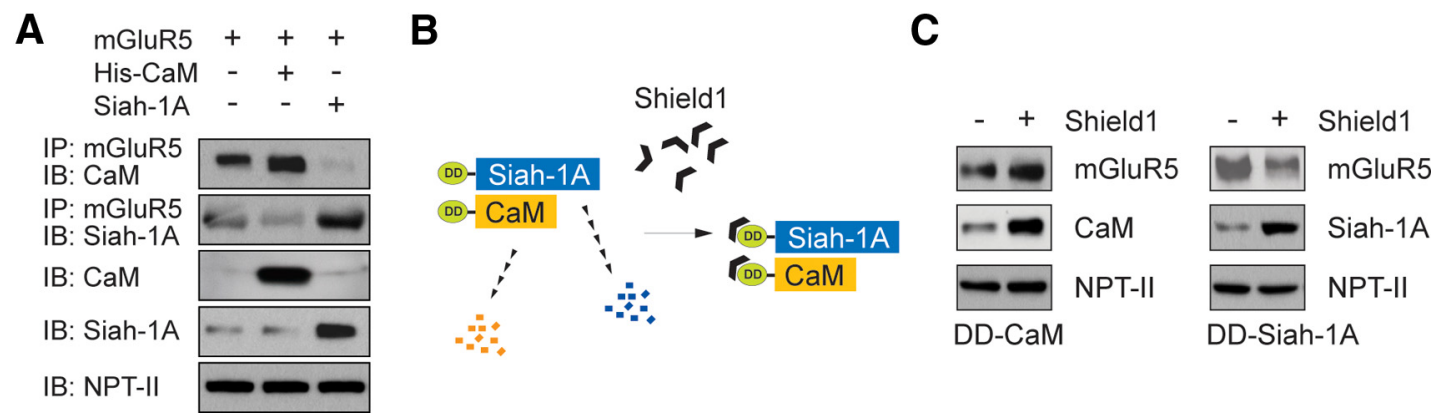

Figure 3. Competition between CaM and Siah-1A for mGluR5 binding. A, HeLa cells were cotransfected with mGluR5 and either CaM or Siah-1A constructs. Immunoprecipitates from mGluR5 antibody incubation were immunoblotted using CaM or Siah-1A antibodies. B, DD was fused to the N terminus of CaM and Siah-1A. Upon treatment of Shield1, the stability of CaM and Siah-1A increased, and rapid regulation of protein levels was achieved at the post-translational level. C, HeLa cells were cotransfected with mGluR5 DNA construct and the DD-linked CaM or Siah-1A DNA construct. Shield1 was added to medium for $3 \mathrm{~h}$ (CaM) or $5 \mathrm{~h}$ (Siah-1A). Changes in mGluR5, CaM, and Siah-1A levels were measured by Western blotting.

mGluR5 (Fig. 5B). According to a previous study (Tiedt et al., 2001), a transcription coactivator, OBF-1, possesses a similar Siah-1A-binding sequence to mGluR5, and mutating the hydrophobic amino acid (V, valine) to an acidic amino acid (E, glutamic acid) drastically disrupted the Siah-1A interaction and inhibited subsequent OBF-1 degradation. Consistent with this report, the mGluR5 I916E mutant exhibited no Siah-1A binding. The most conserved residue among the Siah-1A-binding proteins is the last proline residue in the Siah-1A-binding motif, and this residue is conserved in both group I mGluRs. However, mutation of proline 918 (P918) to alanine had no effect on Siah-1A binding to mGluR5 (Fig. 5B). In contrast, the phosphomimetic mutation of mGluR5 threonine 913 (T913D) disrupted binding with Siah-1A (Fig. 5B). We obtained similar results using a biochemical assay analyzing coimmunopreciptation of mGluR5 and Siah-1A expressed in HeLa cells (Fig. 5C). These results demonstrate that the Siah-1A-binding site is distinct from the CaMbinding site, and hydrophobic interactions between Siah-1A and mGluR5 are important for binding. Because we have not tested the residues beyond the indicated region, there are possibly additional residues that also contribute to binding.

To specifically examine the role of Siah-1A binding in the regulation of mGluR5 surface expression, HeLa cells were transfected with mGluR5 T913D or I916A mutants and subjected to a biotinylation assay to monitor mGluR5 surface expression. The two mutants that disrupted Siah-1A binding to mGluR5 showed increased receptor surface expression (Fig. 5D). We next analyzed mGluR5 surface expression by immunostaining (Fig. $5 E$ ). Here, we used GFP-fused Siah-1A to identify the transfected cells and surface labeling with the Myc antibody to detect cells expressing Myc-mGluR5 on the plasma membrane. We observed almost no surface expression of mGluR5 WT upon Siah-1A coexpression (Fig. 5E, top). In contrast, mGluR5 T913D and mGluR5 I916A were readily detected on the cell surface even in the cells coexpressing Siah-1A (Fig. 5E, middle and bottom), which is consistent with the results from the surface biotinylation assay (Fig. 5D). Last, we tested the effect of the S901D and I916A double mutation on mGluR5 surface expression. Interestingly, mGluR5 S901D, I916A did not display decreased surface expression, consistent with Siah-1A binding being the critical factor underlying the effects of the S901D mutation on mGluR5 surface expression (Fig. 5F). However, mGluR5 I916A did not increase mGluR5 surface expression above that of mGluR5 WT, suggesting that CaM binding and the I916A mutation act cooperatively to inhibit Siah-1A binding to mGluR5 and to increase mGluR5 surface expression. Together, these results demonstrate that
Siah-1A binding is an important factor involved in the regulation of mGluR5 surface trafficking.

\section{Siah-1A binding regulates agonist-induced mGluR5 trafficking}

We next examined the effect of agonist-induced S901 phosphorylation on mGluR5 surface expression. HeLa cells expressing mGluR5 WT or mGluR5 S901A were treated with glutamate for $10 \mathrm{~min}$, and a biotinylation assay was performed to monitor the changes in mGluR5 surface expression. We previously showed that glutamate-induced activation of mGluR5 induces the PKC phosphorylation of $\$ 901$ (Lee et al., 2008). In this study, glutamate treatment decreased mGluR5 surface expression; however, it did not decrease surface mGluR5 S901A, which is not subject to PKC phosphorylation (Fig. 6A). In addition, in the presence of Siah-1A siRNA, the agonist-induced decrease in surface mGluR5 was blocked (Fig. 6B). These results support an important role for Siah-1A in regulating mGluR5 trafficking following agoniststimulated mGluR5 S901 phosphorylation.

\section{In situ detection of agonist-dependent mGluR5-Siah-1A interaction}

To assess whether competition between CaM and Siah-1A for mGluR5 binding also occurs in primary cultured hippocampal neurons, we studied mGluR5 and Siah-1A interactions in situ using the Duolink PLA (see Materials and Methods). In brief, we label neurons with CaM and Siah-1A antibodies and subsequently with species-specific secondary antibodies (so that each secondary antibody specifically recognizes only 1 primary antibody). The secondary antibodies are attached to DNA strands that participate in a series of reactions (ligation, replication, and hybridization with fluorescently labeled detection oligonucleotides) that can only occur when the two proteins are in close proximity $(<40 \mathrm{~nm})$. Therefore, PLA offers valuable in situ information about protein-protein interactions, although it is semiquantitative due to limited dynamic range of detection. We specifically monitored protein binding following agonistinduced mGluR5 activation, which causes CaM displacement due to S901 phosphorylation (Lee et al., 2008). First, we determined that Siah-1A interacts with mGluR5 in brain lysates (Fig. $7 A$ ) with an immunoprecipitation study. PLA probes for mGluR5 and Siah-1A antibodies showed that the two proteins interacted primarily along neurites and the cell body, which appear as fluorescent spots (Fig. 7B). These experiments reveal an interaction between mGluR5 and Siah-1A within intact neurons. Because 3,5-dihydroxyphenylglycine (DHPG), an mGluR5 ago- 
A

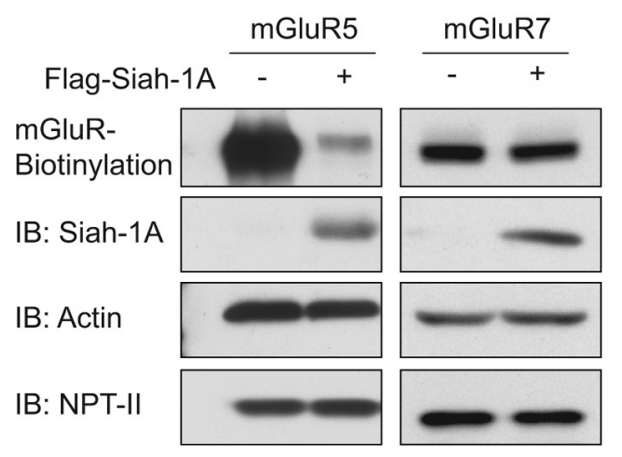

C

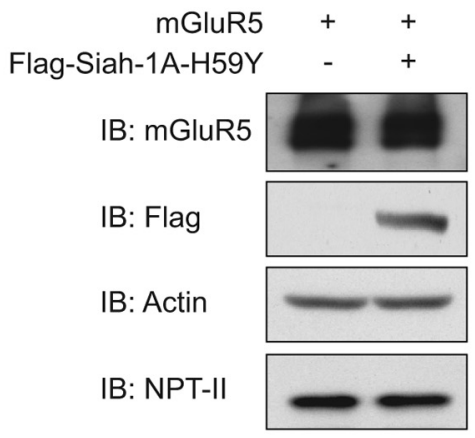

$\mathbf{F}$

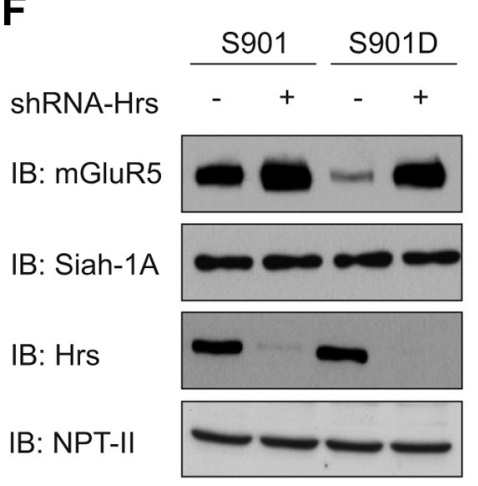

B

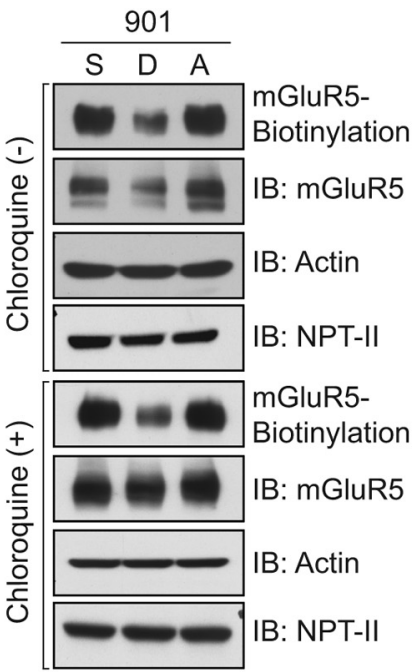

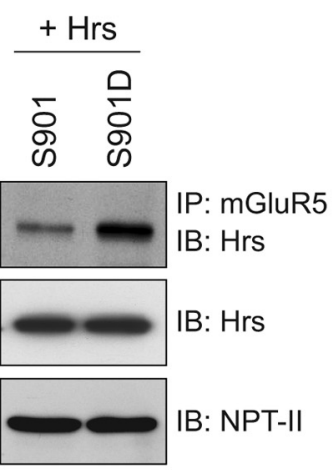

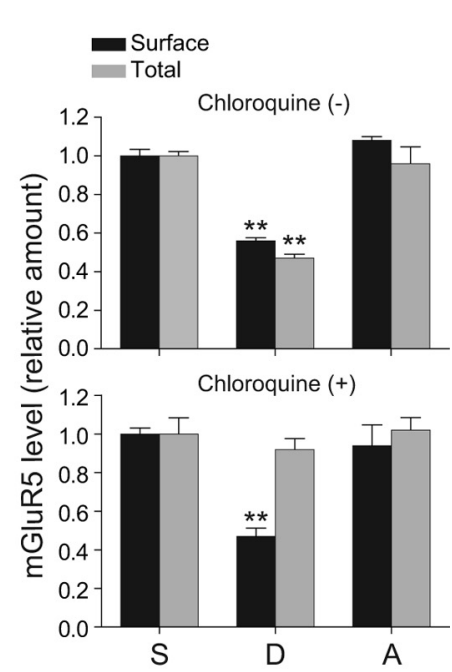

E
D

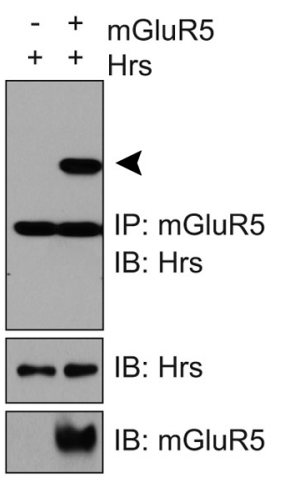

G

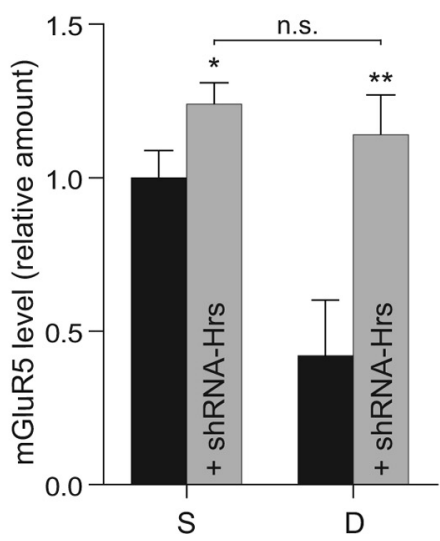

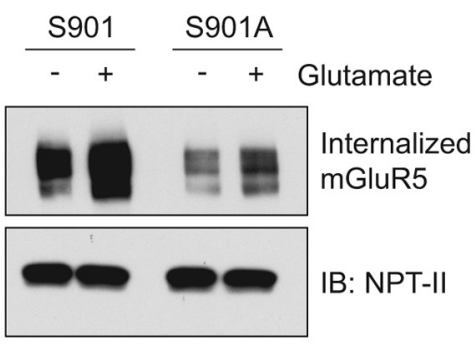

Figure 4. Siah-1A regulation of mGluR5 surface trafficking. $A$, HeLa cells were transfected with mGluR5 with or without Siah-1A. Surface expression of mGluR5 was analyzed by a biotinylation assay. Biotinylated fractions were immunoblotted with mGluR5 antibodies. The same experiment was performed for mGluR7 using mGluR7 antibodies. $\boldsymbol{B}$, Biotinylation assays were performed in cells transfected with mGluR5 WT (S), S901D, or S901A mutants in the absence or presence of chloroquine ( $25 \mu \mathrm{m})$ for $6 \mathrm{~h}$. Purified biotinylated surface proteins or total cell lysates were immunoblotted using mGluR5 antibodies. Quantitative measurement of mGluR5 levels from biotinylated surface proteins and total cell lysates (right). $\mathrm{mGluR5}$ surface expression were normalized to NPT-II and expressed as fold changes over that of control cells expressing mGluR5 WT. Data represent the mean values ( \pm SEM). One-way ANOVA [surface/chloroquine (-): $F_{(2,9)}=198.1, p<0.0001$; total/chloroquine $(-): F_{(2,9)}=52.68, p<0.0001$; surface/chloroquine $(+): F_{(2,9)}=49.26, p<0.0001$; total/chloroquine $(+)$ : $\left.F_{(2,9)}=0.9102, p<0.4365\right]$, followed by Bonferroni-Dunn post hoc test for multiple comparisons. ${ }^{* *} p<0.01$ compared with mGluR5 WT (S). C, HeLa cells were transfected with mGluR5 and/or Siah-1A-H59Y mutant. Western blotting was performed to monitor mGluR5 protein levels. $\boldsymbol{D}$, Lysates from HeLa cells cotransfected with mGluR5 and Hrs were subjected to immunoprecipitation assays. Arrowhead indicates the band representing Hrs. $\boldsymbol{E}$, HeLa cells were cotransfected with Hrs and mGluR5 WT or mGluR5 S901D. Immunoprecipitates isolated with mGluR5 antibody were subjected to Western blotting with Hrs antibody. $F$, mGluR5 WT or S901D mutant was cotransfected into HeLa cells with control shRNA (nontargeted shRNA) or shRNA against Hrs. mGluR5 levels were measured by Western blotting. One-way ANOVA $\left(F_{(3,12)}=36.85, p<0.0001\right)$, followed by Bonferroni-Dunn post hoc test for multiple comparisons. ${ }^{*} p<0.05$ compared with mGluR5 WT (S) with nontargeted shRNA and ${ }^{* *} p<0.01$ compared with mGluR5 S901D with nontargeted shRNA. G, HeLa cells were transfected with mGluR5 WT or mGluR5 S901A. Cells were biotinylated and then treated with glutamate (100 $\mu \mathrm{m})$ for $5 \mathrm{~min}$. Remaining biotinylated mGluR5 was cleaved by reduced glutathione to detect internalized biotinylated mGluR5. 
B

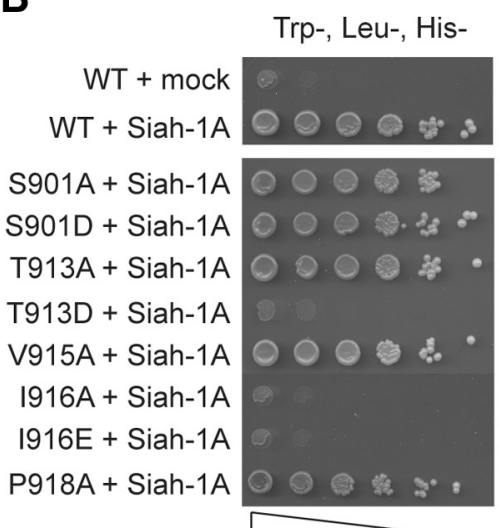

E
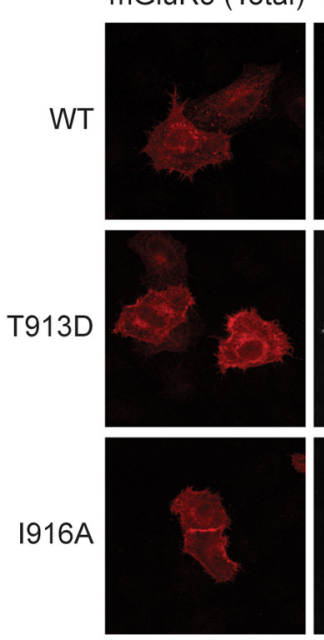
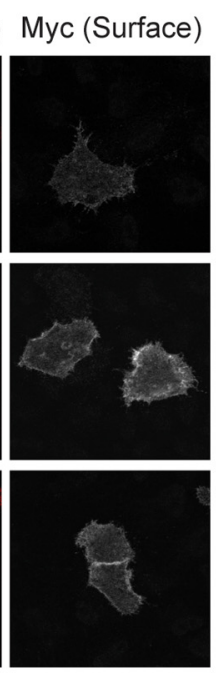

I916A

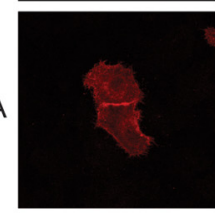

Trp-, Leu-

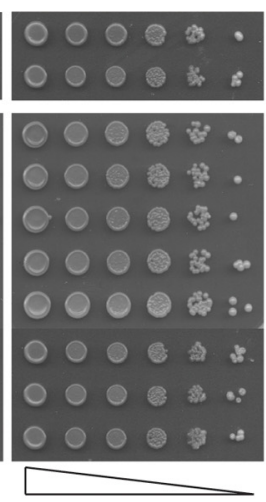

GFP-Siah-1A
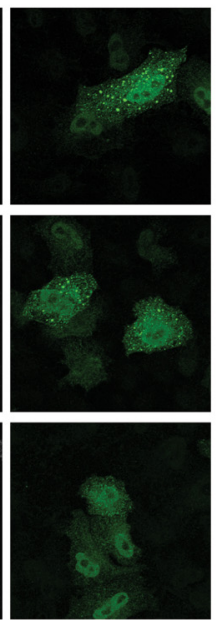

C

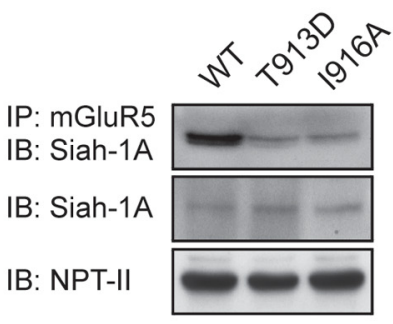

D

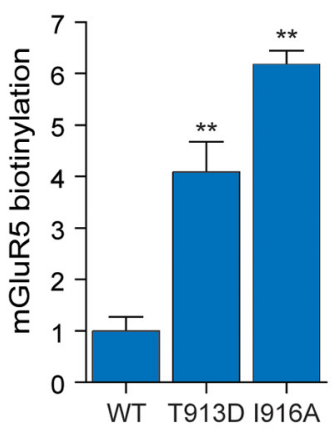

F

mGluR5 biotinylation

IB: Actin

IB: NPT-II

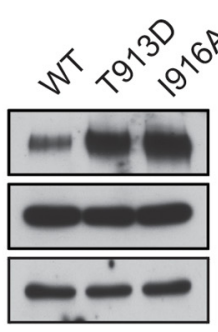

mGluR5biotinylation

IB: Actin

IB: NPT-II

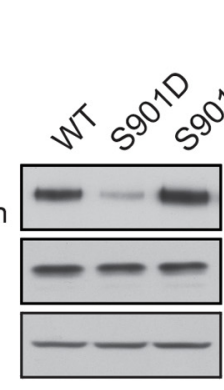

Figure 5. Mutations disrupting Siah-1A-mGluR5 binding affect mGluR5 trafficking. A, Sequence of a portion of the mGluR5 C terminus containing critical binding domains (889-918; CaMbinding domain 889-917 and Siah-1A-binding domain 892-918). The Siah-1A-binding consensus sequence (PXAXVXP, X = any amino acid) is indicated at the top. Arrows indicate S901, T913, and 1916 on mGluR5. B, mGluR5 T913D, mGluR5 1916A, and mGluR5 1916E did not interact with Siah-1A in yeast two-hybrid assays. Yeasts were cotransformed with LexA-mGluR5 (828 -944) (WT, S901A, S901D, T913A, T913D, V915A, 1916A, 1916E, or P918A) and Gal4-Siah-1A, and growth was evaluated. Results shown are 10-fold serial dilutions of yeast cells. All data shown are representative of at least three independent experiments. C, HeLa cells were cotransfected with mGluR5 WT, mGluR5 T913D, or mGluR5 I916A and subjected to a coimmunoprecipitation assay. D, HeLa cells were transfected with mGluR5 WT, T913D, or 1916A mutants. Surface expression levels of mGluR5 and its mutants were measured by a surface biotinylation assay. mGluR5 surface expression was quantified by measuring the band intensity of mGluR5 and normalized to NPT-II expression. Data represent the mean values $( \pm \operatorname{SEM})$. One-way ANOVA $\left(F_{(2,12)}=174.5, p<0.0001\right)$, followed by Bonferroni-Dunn post hoc test for multiple comparisons. ** $p 0.01$ compared with mGluR5 WT (S). E, Cell surface labeling of mGluR5 WT, T913D, or 1916A in HeLa cells. Live HeLa cells cotransfected with GFP-Siah-1A and Myc-mGluR5 WT, T913D, and 1916A were labeled with mouse anti-Myc antibodies (surface) and Alexa 647-conjugated secondary antibodies (shown as white). After permeabilization, the cells were labeled with rabbit anti-mGluR5 antibodies (total) and Alexa 568-conjugated secondary antibodies (red). GFP-Siah-1A was labeled with chicken anti-GFP antibodies and Alexa 488-conjugated secondary antibodies (green). $\boldsymbol{F}$, HeLa cells were transfected with mGluR5 WT, mGluR5 S901D, or mGluR5 S901D and I916A double mutants. A biotinylation assay was performed for WT and mutant mGluR5 surface expression. Data represent the mean values ( \pm SEM). One-way ANOVA $\left(F_{(2.12)}=53.60, p<0.0001\right)$, followed by Bonferroni-Dunn post hoc test for multiple comparisons. ${ }^{* *} p<0.01$ compared with mGluR5 WT (S).

nist, was shown to induce phosphorylation of mGluR5 S901 in a PKC-dependent manner (Lee et al., 2008), we treated neurons with DHPG for $15 \mathrm{~min}$ and then subjected them to PLA. Compared with no treatment, the fluorescent spots representing the interaction between mGluR5 and Siah-1A were increased upon treatment of DHPG (Fig. $7 B, C$ ), indicating that dynamic interaction of Siah-1A with mGluR5 is an event that occurs upon mGluR5 activation in neuronal cells.

\section{Siah-1A-mediated regulation of mGluR5 trafficking in} hippocampal neurons

To evaluate the effect of Siah-1A on mGluR5 trafficking in primary cultured hippocampal neurons, we transfected neurons with EGFP or Siah-1A-EGFP. Cell surface expression of mGluR5 was detected using an mGluR5 antibody directed against the mGluR5 extracellular domain (amino acids 367-380 of rat mGluR5). The mGluR5 signal specificity was confirmed by ob- 
A

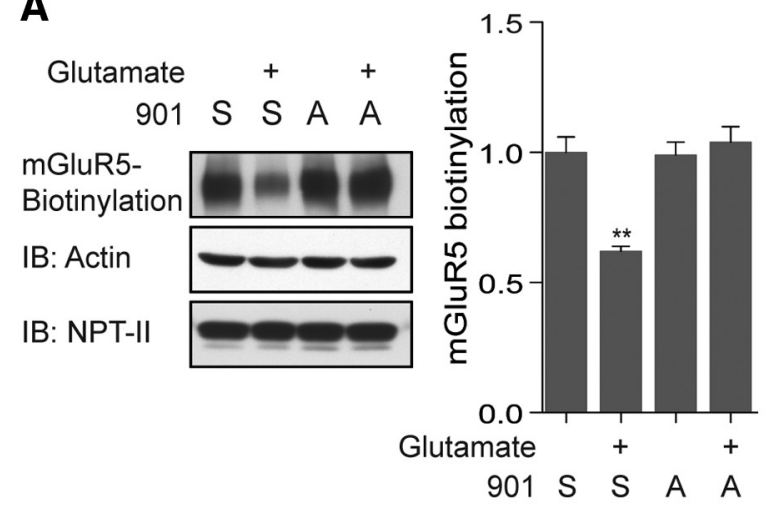

B

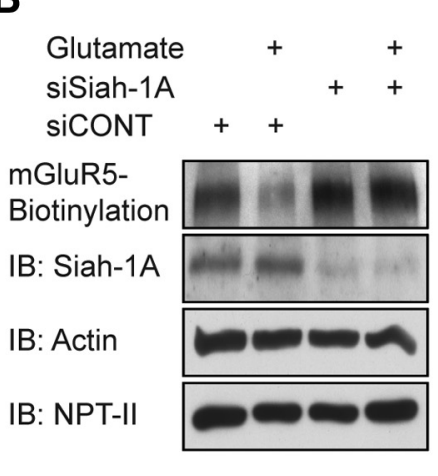

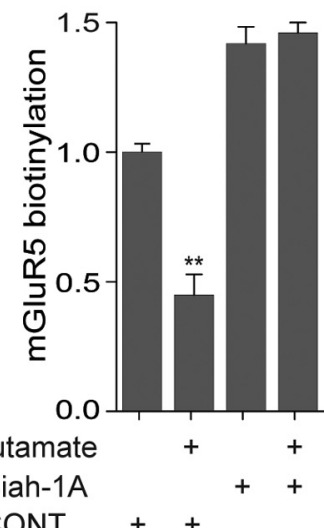

Figure 6. Effect of Siah-1A on agonist-induced changes in mGluR5 surface expression. $A$, HeLa cells expressing mGluR5 WT or mGluR5 S901A were stimulated with glutamate (100 $\mu$ M) for 10 min, and the lysates were subjected to a surface biotinylation assay. Data in the histogram represent the mean values ( \pm SEM). One-way ANOVA $\left(F_{(3,12)}=41.64, p<0.0001\right)$, followed by BonferroniDunn post hoc test for multiple comparisons. ${ }^{* *} p<0.01$ compared with mGluR5 WT (S) without glutamate. B, HeLa cells treated with siCONT (nontargeted siRNA pool) or siSiah-1A (siRNA pool against Siah-1A) were transfected with mGluR5 and stimulated with glutamate $(100 \mu \mathrm{M})$ for $10 \mathrm{~min}$. Cell lysates were subject to a surface biotinylation assay. Data in the histogram represent the mean values ( \pm SEM). One-way ANOVA $\left(F_{(3,12)}=72.06, p<0.0001\right)$, followed by Bonferroni-Dunn post hoc test for multiple comparisons. ${ }^{*} p<0.01$ compared with mGluR5 WT $(S)$ without glutamate. In $\boldsymbol{A}$ and $\boldsymbol{B}, \mathrm{mGluR5}$ biotinylation levels were normalized to NPT-II and expressed as fold changes over that of control cells expressing mGluR5 WT.

A

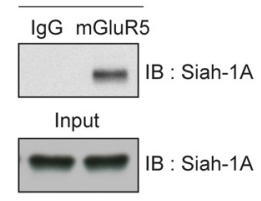

C

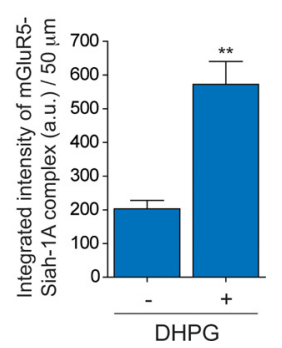

B

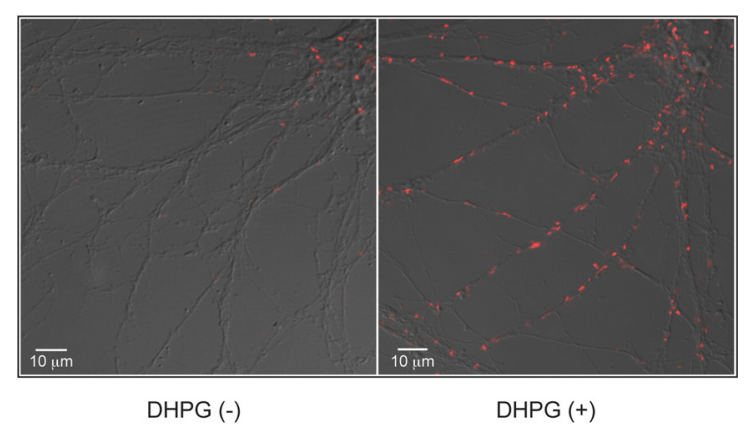

DHPG (-)

tion of CaM binding to mGluR5 leading to alterations in the receptor trafficking (Lee et al., 2008). Because the amino acid sequences for CaM and Siah-1A binding overlap considerably (Fig. 1A), we predicted that S901 phosphorylation might also affect Siah-1A binding to mGluR5. Using several assays, we have now shown that PKC phosphorylation enhances Siah-1A binding. However, using an in vitro pull-down assay, we demonstrated that S901 phosphorylation inhibited the binding of CaM, but did not affect Siah-1A binding in the absence of CaM. This suggests that CaM binding itself plays a central role in regulating interactions between mGluR5 and Siah-1A and is the necessary protein to modulate phosphorylation-dependent Siah-1A effects. We tested this hypothesis using a variety of approaches, and indeed found that PKC phosphorylation of mGluR5 on S901 dramatically affects receptor trafficking and lysosomal degradation by promoting Siah-1A binding. We also define the critical residues within the Siah-1Abinding site and show that PKC phosphorserving signal loss when the cells were preincubated with a control peptide corresponding to amino acids 367-380 of rat mGluR5 (data not shown). Siah-1A decreased the mGluR5 fluorescent cell surface signal compared with the control (Fig. $8 A, B$ ), indicating that Siah-1A can regulate mGluR5 trafficking in hippocampal neurons.

\section{Discussion}

A large number of mGluR5 binding proteins have been identified, including $\mathrm{CaM}$ and Siah-1A. An in vitro binding assay using mGluR5 C-terminal fusion proteins first showed that CaM and Siah-1A interact with mGluR5 in a mutually exclusive way (Ishikawa et al., 1999). However, the relevance of this interaction in situ and in neurons and the molecular events that affect the binding activities have not yet been elucidated. The phosphorylation of mGluR5 S901 was the first example of dynamic regula-

ylation effects on trafficking are exquisitely sensitive to Siah-1A binding.

Recently, norbin, which is another mGluR5-binding protein and is involved in the development of schizophrenic phenotypes in mice, has been reported to compete with CaM for mGluR5 binding (Wang et al., 2009). Interestingly, the binding motif for norbin on the mGluR5 C terminus highly overlaps with the CaMbinding site (Wang et al., 2009). Thus, it is likely that S901 phosphorylation also regulates norbin binding by modulating the interaction of CaM with mGluR5, which would provide another example of CaM regulating an mGluR5-binding protein. Similar competitive binding has been reported with other GPCRs. For example, CaM competes with G-proteins for binding to the $\mu$-opioid receptor (Wang et al., 1999). It also antagonizes PKC 
binding to $5-\mathrm{HT}_{1 \mathrm{~A}}$ and 5- $\mathrm{HT}_{2 \mathrm{~A}}$ (Turner et al., 2004; Turner and Raymond, 2005). In contrast, CaM can also function to stabilize the interaction of binding proteins to GPCRs. For example, the $5-\mathrm{HT}_{2 \mathrm{C}}$ and $\beta$-arrestin complex is stabilized by $\mathrm{CaM}$ (Labasque et al., 2008). Together, these findings indicate that CaM may act as a panregulator of GPCR function by enhancing or displacing GPCR-binding proteins.

The group III mGluR mGluR7 also binds to CaM. However, in contrast to mGluR5, CaM dissociation from mGluR7 promotes its trafficking to the cell surface (Suh et al., 2008). Because Siah-1A does not bind to mGluR7 (Moriyoshi et al., 2004), it is plausible to assume that other CaM-competing mGluR7-binding proteins may inversely affect the distribution of mGluR7 (Suh et al., 2008). Indeed, the mGluR7-binding protein PICK1 competes with CaM for receptor binding and increases the surface expression of mGluR7. PICK1 is also interesting because it binds to the extreme $\mathrm{C}$ terminus of mGluR7, which is far from the CaM-binding domain, indicating that the competition between CaM and other binding proteins is not only relevant for two proteins with overlapping binding sites. Together, these studies also support the notion that CaM can modulate receptor function indirectly by regulating other receptor-binding proteins, as seen with Siah-1A, which directly impacts mGluR5 trafficking.

One important question is how Siah-1A regulates mGluR5 trafficking. Siah-1A functions as an E3 ligase for the group I mGluRs (mGluR1 and mGluR5), as it promotes the ubiquitination of the receptor (Moriyoshi et al., 2004). The degradation of a number of GPCRs occurs via lysosomal sorting, and the covalent attachment of ubiquitin to the receptor can initiate this process (Hanyaloglu and von Zastrow, 2008). Receptor ubiquitination is also involved in initiating receptor endocytosis. For example, the Cbl family of ubiquitin ligases mediates the ubiquitination of epidermal growth factor receptor, which is essential for both receptor endocytosis and translocation to lysosomes for degradation (Haglund et al., 2003a; Mosesson et al., 2003). In our study, enhanced degradation of mGluR5 S901D compared with mGluR5 WT was a consequence of enhanced Siah-1A binding to mGluR5. However, a lysosomal inhibitor selectively reversed the decrease in total mGluR5 S901D protein levels, but not surface mGluR5 S901D, consistent with Siah-1A actively regulating particular steps in the endocytic or lysosomal sorting pathways.

Siah-1A is responsible for both monoubiquitination and polyubiquitination (Rott et al., 2008; Winter et al., 2008). Generally, polyubiquitination signals proteasomal degradation, and monoubiquitination signals receptor sorting to late endosomes and subsequent lysosomal degradation (Haglund et al., 2003b). A GPCR, like mGluR5, undergoes endocytosis and enters into an early endosome, where it will either recycle back to the membrane or sort into the late endosomal/lysosomal pathway for degradation. In our model, Siah-1A binding to mGluR5 would trigger monoubiquitination of the receptor and target the receptor into the late endosomal/lysosomal pathway. This model is further supported by our demonstration of an interaction between Siah-1A and Hrs and increased stability of mGluR 5 by Hrs deletion. These findings are consistent with Siah-1A binding to
mGluR5 and sorting the receptor into the lysosomal trafficking pathway.

mGluR5 plays important roles in both synaptic plasticity and neuronal development. For many glutamate receptors, such as NMDA, AMPA, kainate, and metabotropic glutamate receptors, which are involved in the regulation of synaptic plasticity, two events are essential for regulating synaptic strength: receptorinduced increases in intracellular calcium levels and phosphorylation of the glutamate receptors (Chen and Roche, 2007; Kim et al., 2008). mGluR5 also appears to be subject to these two important processes: mGluR5-induced calcium release results in CaM activation, which is a calcium-sensor protein, and $\mathrm{PKC}$ dependent phosphorylation of residue S901 occurs after receptor activation (Kim et al., 2005; Lee et al., 2008). Interestingly, mGluR5 activation could initiate two potentially conflicting events. mGluR5-induced calcium release enhances CaM binding to mGluR5; however, mGluR5 activation-induced PKC phosphorylation of S901 displaces CaM. In our experimental model, when mGluR5 was solely activated in heterologous cells and primary cultured hippocampal neurons, S901 phosphorylation appeared to circumvent the potentially enhanced CaM affinity, as mGluR5 activation decreased stabilization of mGluR 5 on the surface and enhanced Siah-1A binding to mGluR5. However, under in vivo conditions, numerous brain channels and receptors exist that could increase intracellular free calcium and/or activate protein kinases/phosphatases and could be activated together or sequentially in distinct contexts for synaptic transmission and plasticity. Thus, different synaptic transmission stages or modes may confer varied receptor-binding capacities for CaM, which would affect the ultimate effects on mGluR5 trafficking. These seemingly contradictory regulatory mechanisms for the CaM and mGluR5 interactions, when reconciled, could place CaM in a central role for the integration of various synaptic signals.

Strict control of mGluR5 activity is critical for preventing neurological and psychological diseases. mGluR5 reduction or knock-out has been shown to suppress anxiety and depression. In fragile X mental retardation disease, uncontrolled mGluR5 signaling due to the absence of the fragile $\mathrm{X}$ mental retardation protein is considered the primary pathological mechanism (Krueger and Bear, 2011). Recently, the deletion of norbin, which has CaM-like positive effects on mGluR5 surface expression and signaling, was reported to aggravate schizophrenic symptoms in animal models (Wang et al., 2009). Considering these results, fine-tuning of synaptic receptor signaling is critical for normal 
brain function. In the current study, CaM-Siah-1A interactions were shown to be important for the regulation of neuronal mGluR5 trafficking by controlling the number of receptors on the cell surface. However, it remains to be determined why neurons use CaM indirectly to modulate the binding efficacy of other mGluR5-binding proteins rather than directly regulating each protein through receptor modifications, such as phosphorylation. Future studies to address this question will greatly enhance our understanding of GPCR functions and the pathophysiology of mGluR5-related diseases in the CNS.

\section{References}

Banaszynski LA, Chen LC, Maynard-Smith LA, Ooi AG, Wandless TJ (2006) A Rapid, reversible, and tunable method to regulate protein function in living cells using synthetic small molecules. Cell 126:995-1004.

Chen BS, Roche KW (2007) Regulation of NMDA receptors by phosphorylation. Neuropharmacology 53:362-368.

Chin D, Means AR (2000) Calmodulin: a prototypical calcium sensor. Trends Cell Biol 10:322-328.

Dölen G, Osterweil E, Rao BS, Smith GB, Auerbach BD, Chattarji S, Bear MF (2007) Correction of fragile X syndrome in mice. Neuron 56:955-962.

Farr A, Roman A (1992) A pitfall of using a second plasmid to determine transfection efficiency. Nucleic Acids Res 20:920.

Haglund K, Sigismund S, Polo S, Szymkiewicz I, Di Fiore PP, Dikic I (2003a) Multiple monoubiquitination of RTKs is sufficient for their endocytosis and degradation. Nat Cell Biol 5:461-466.

Haglund K, Di Fiore PP, Dikic I (2003b) Distinct monoubiquitin signals in receptor endocytosis. Trends Biochem Sci 28:598-603.

Hanyaloglu AC, von Zastrow M (2008) Regulation of GPCRs by endocytic membrane trafficking and its potential implications. Annu Rev Pharmacol Toxicol 48:537-568.

House CM, Frew IJ, Huang HL, Wiche G, Traficante N, Nice E, Catimel B, Bowtell DD (2003) A binding motif for Siah ubiquitin ligase. Proc Natl Acad Sci U S A 100:3101-3106.

Ishikawa K, Nash SR, Nishimune A, Neki A, Kaneko S, Nakanishi S (1999) Competitive interaction of seven in absentia homolog-1A and $\mathrm{Ca} 2+1$ calmodulin with the cytoplasmic tail of group 1 metabotropic glutamate receptors. Genes Cells 4:381-390.

Kim CH, Braud S, Isaac JT, Roche KW (2005) Protein kinase C phosphorylation of the metabotropic glutamate receptor mGluR5 on Serine 839 regulates Ca2 + oscillations. J Biol Chem 280:25409-25415.

Kim CH, Lee J, Lee JY, Roche KW (2008) Metabotropic glutamate receptors: phosphorylation and receptor signaling. J Neurosci Res 86:1-10.

Krueger DD, Bear MF (2011) Toward fulfilling the promise of molecular medicine in fragile X syndrome. Annu Rev Med 62:411-429.

Krystal JH, Mathew SJ, D’Souza DC, Garakani A, Gunduz-Bruce H, Charney DS (2010) Potential psychiatric applications of metabotropic glutamate receptor agonists and antagonists. CNS Drugs 24:669-693.

Labasque M, Reiter E, Becamel C, Bockaert J, Marin P (2008) Physical interaction of calmodulin with the 5-hydroxytryptamine2C receptor C-terminus is essential for $\mathrm{G}$ protein-independent, arrestin-dependent receptor signaling. Mol Biol Cell 19:4640-4650.

Lee JH, Lee J, Choi KY, Hepp R, Lee JY, Lim MK, Chatani-Hinze M, Roche
PA, Kim DG, Ahn YS, Kim CH, Roche KW (2008) Calmodulin dynamically regulates the trafficking of the metabotropic glutamate receptor mGluR5. Proc Natl Acad Sci U S A 105:12575-12580.

Lüscher C, Huber KM (2010) Group 1 mGluR-dependent synaptic longterm depression: mechanisms and implications for circuitry and disease. Neuron 65:445-459.

Moriyoshi K, Iijima K, Fujii H, Ito H, Cho Y, Nakanishi S (2004) Seven in absentia homolog $1 \mathrm{~A}$ mediates ubiquitination and degradation of group 1 metabotropic glutamate receptors. Proc Natl Acad Sci U S A 101:8614-8619.

Mosesson Y, Shtiegman K, Katz M, Zwang Y, Vereb G, Szollosi J, Yarden Y (2003) Endocytosis of receptor tyrosine kinases is driven by monoubiquitylation, not polyubiquitylation. J Biol Chem 278:21323-21326.

Navarro G, Aymerich MS, Marcellino D, Cortés A, Casad ó V, Mallol J, Canela EI, Agnati L, Woods AS, Fuxe K, Lluís C, Lanciego JL, Ferr é S, Franco R (2009) Interactions between calmodulin, adenosine A2A, and dopamine D2 receptors. J Biol Chem 284:28058-28068.

Niswender CM, Conn PJ (2010) Metabotropic glutamate receptors: physiology, pharmacology, and disease. Annu Rev Pharmacol Toxicol 50:295-322.

Rott R, Szargel R, Haskin J, Shani V, Shainskaya A, Manov I, Liani E, Avraham E, Engelender S (2008) Monoubiquitylation of alpha-synuclein by seven in absentia homolog (SIAH) promotes its aggregation in dopaminergic cells. J Biol Chem 283:3316-3328.

Suh YH, Pelkey KA, Lavezzari G, Roche PA, Huganir RL, McBain CJ, Roche KW (2008) Corequirement of PICK1 binding and PKC phosphorylation for stable surface expression of the metabotropic glutamate receptor mGluR7. Neuron 58:736-748.

Tiedt R, Bartholdy BA, Matthias G, Newell JW, Matthias P (2001) The RING finger protein Siah-1 regulates the level of the transcriptional coactivator OBF-1. EMBO J 20:4143-4152.

Turner JH, Raymond JR (2005) Interaction of calmodulin with the serotonin 5-hydroxytryptamine2A receptor. A putative regulator of $\mathrm{G}$ protein coupling and receptor phosphorylation by protein kinase C. J Biol Chem 280:30741-30750.

Turner JH, Gelasco AK, Raymond JR (2004) Calmodulin interacts with the third intracellular loop of the serotonin 5-hydroxytryptamine1A receptor at two distinct sites: putative role in receptor phosphorylation by protein kinase C. J Biol Chem 279:17027-17037.

Wang D, Sadée W, Quillan JM (1999) Calmodulin binding to G proteincoupling domain of opioid receptors. J Biol Chem 274:22081-22088.

Wang H, Westin L, Nong Y, Birnbaum S, Bendor J, Brismar H, Nestler E, Aperia A, Flajolet M, Greengard P (2009) Norbin is an endogenous regulator of metabotropic glutamate receptor 5 signaling. Science 326:1554-1557.

Wheeler TC, Chin LS, Li Y, Roudabush FL, Li L (2002) Regulation of synaptophysin degradation by mammalian homologues of seven in absentia. J Biol Chem 277:10273-10282.

Winter M, Sombroek D, Dauth I, Moehlenbrink J, Scheuermann K, Crone J, Hofmann TG (2008) Control of HIPK2 stability by ubiquitin ligase Siah-1 and checkpoint kinases ATM and ATR. Nat Cell Biol 10:812-824.

Wollert T, Yang D, Ren X, Lee HH, Im YJ, Hurley JH (2009) The ESCRT machinery at a glance. J Cell Sci 122:2163-2166.

Xia Z, Storm DR (2005) The role of calmodulin as a signal integrator for synaptic plasticity. Nat Rev Neurosci 6:267-276. 